\title{
Observing marine pollution with Synthetic Aperture Radar
}

\author{
Paolo Trivero and Walter Biamino \\ Università del Piemonte Orientale "Amedeo Avogadro", Alessandria \\ Italy
}

\section{Introduction}

Marine pollution is a matter of public concern because of its strong influence on various human activities such as fisheries and tourism, as well as for consequences on health. In this context, particular attention is being paid to pollution phenomena on the sea surface, where even a small amount of substance can spread over a large area in the form of a thin film.

A great aid in the effort of monitoring sea surface pollution comes from remote sensing techniques. Satellite - borne instruments are able to monitor wide areas and to detect the presence of surface slicks; optical instrument can do this by evaluating the change in spectral components of visible and infrared radiation, but they are unable to work during the night or in bad weather (clouds) conditions. For this reason, active microwave instruments play a key role in sea surface observation because electromagnetic waves freely propagate in atmosphere and in clouds.

The aim of this chapter is to explain the usefulness of the Synthetic Aperture Radar (SAR) as a tool for sea surface monitoring, especially to detect pollution. This happens because a number of pollutant substances produce huge areas of surface film which reduce water surface roughness and therefore they can be detected by the Normalized Radar CrossSection (NRCS) on SAR images where they appear as dark areas.

Theoretical basis and practical applications will be described by reviewing literature, in order to give a comprehensive view about fundamental concept and the latest advances.

Theoretical and experimental studies, carried out over the last decades, demonstrate that the presence of a monomolecular film is able to modify the spectra of short sea waves. The damping ratio, e.g. the ratio between the spectra with clean and slick covered water, shows a maximum in the frequency domain, strongly dependent on slick composition and thickness.

Sea surface roughness is due to the short waves (wavelength up to a few tenths of centimetres) appearing on sea surface due to external forcing such as wind. The dynamics of those short waves (wavelength, velocity, etc.) is driven by the physical characteristics of sea water such as density and surface tension. The presence of a surface film modifies the surface tension and therefore causes a noticeable damping of centimetric waves: the slick covered area appears "flatter" than the surrounding sea. 
Water surface strongly reflects microwaves; water vapour is transparent instead. SAR is a powerful instrument to detect the presence of surface active pollutants, able to operate regardless of sunlight and weather conditions. The SAR sends microwaves towards the earth and collects the echoes from many radar pulses, processing them into a single radar image, allowing high spatial resolutions; radio pulses are sent with high incidence angles and therefore scattered by sea surface roughness. Radio wavelengths currently used by SAR are Bragg resonant with centimetric water waves: different scattered signals are summed with constructive interference and therefore easily detected.

Marine ecosystems are threatened by various pollution phenomena with possible consequences for vegetal and animal forms of life. Some pollutants appear as thin films on sea surface, spreading over large areas: this is the case of insoluble surfactant substances such as hydrocarbons, coming from pipelines or tank leakage, as well as illegal discharges in open seas or natural seeps. Other pollutants, whilst being water soluble, may produce macroscopic effects on the surface: a typical example is given by organic substances from sewage and land runoff, carried by rivers and then dissolved in sea; chemical modifications in seawater composition can cause algae to bloom, which in turn produces mucilage on the surface.

Surface films are able to modify water dynamics, inhibiting gas exchanges and strongly modifying the formation of short waves. This is the key point for understanding how SAR can be used for remote sensing of marine pollution episodes.

Satellite - borne SARs have been used since 1978 for sea surface monitoring, as well as for mapping applications; there are today various different satellites carrying SAR instruments with different technical characteristics.

The state-of-the-art of SAR instruments and data analysis procedures will be presented, with a special focus on algorithm for automatic features extraction from SAR images. The limits of those technologies will be also evidenced; front-end technologies and future planned advances will be pointed out.

A number of operational services are currently managed and maintained by public and private bodies. A review will be carried out, in order to give a comprehensive view on practical issues and advantages.

\section{Water surface slicks}

Water surface slicks have several terrestrial and marine sources. Most of them are constituted by hydrophobic material naturally yielded, for instance as surfactant exuding from phytoplankton, composed mainly by homo- and hetero-polysaccharides, found at sea surface during phytoplankton blossoming (Zutic et al. 1981). Other natural sources come from land, such as the products of vegetables degradation carried by rivers to sea, and can have man-made origins such as industrial and oil plants or agricultural activities; furthermore, high concentrations of surfactants are found in urban waste water (Liss et al. 1997). Both soluble and insoluble surface-active substances are present at air-sea interfaces. The chemical nature and surface concentrations of these materials are influenced by environmental factors, such as distance from shore, local bio ecology, influx of man-made effluents from ships and meteorological conditions. Wave motion tends to select and accumulate organic materials in relation at their surface activity. With age, the films become progressively more water insoluble. Aged films and slicks generally involve multilayered 
structure and weak cohesion under wind action, manifesting a tendency to break up to into macroscopic discontinuities. These films, concentrated at air-sea interface, cover large oceanic surfaces. Even when their concentration is low, they can show important effects, such as alterations in the structure of surface waves, foam formation, modification of gas exchange at interface and changes in the behaviour of backscattering of electromagnetic waves at sea surface. Natural surfactants reduce gas transfer and short waves amplitude (Goldmann and Dennet 1983, Bock et al. 1999) and in general films at sea surface can influence energy dissipation of capillary waves (Lucassen-Reynders and Lucassen, 1969; Huhnerfuss et al. 1987) and gas exchange rates (Frew et al. 1990).

In the more soluble adsorption films the relaxation process is essentially of a diffusional nature. The intermolecular forces between the adsorbed film molecules resist complete displacement from the surface by wind and wave dynamics and are of the same order as that of the solvent, since surface-active molecules are completely hydrated. In the more water-insoluble spreading films, however, when the surface concentration is high, interaction forces among hydrophobic chains are strong, and may even reach twodimensional micellar conditions. Here the relaxation phenomenon involves structural rearrangement. Consequently, one should expect ripple-damping effects, which are greater for insoluble films than for films with greater seawater solubility.

The damping of short ocean surface waves by surfactant films is a well investigated phenomenon (Lucassen-Reynders and Lucassen, 1969; Huhnerfuss and Garrett, 1981; Lucassen, 1982; Huhnerfuss, 1986; Ermakov et al., 1986; Alpers and Huhnerfuss, 1988; 1989; Wu, 1989; Wei and Wu, 1992; Frysinger et al., 1992; Onstott and Rufenach, 1992; Huhnerfuss et al., 1994; 1996).

The theory of rheology of air-water interfaces predicts a maximum in the frequency response of the ratio of the damping coefficient of short-gravity waves for water covered by an organic surface film to the coefficient for a pure water surface (Cini and Lombardini 1978). The theoretical analysis, based upon the Navier-Stokes equation and developed for the case of small ripples on an interface covered by a surface-active substance, has been extended by with a formalism which includes both soluble and insoluble monomolecular films for the two coexisting modal solutions: the Laplace or transversal mode and the Marangoni or longitudinal mode (Lombardini et al. 1982, Fiscella et al. 1985a).

According to Lombardini et al. (1989), the analytical form which describes the ratio between real parts of the complex radian frequencies on pure water to that for water covered by slick (damping ratio) can be given by the semi - empirical formula:

$$
y(f)_{\mathrm{s}}=\frac{1 \pm 2 \tau+2 \tau^{2}-X+Y(X+\tau)}{1 \pm 2 \tau+2 \tau^{2}-2 X+2 X^{2}}
$$

Where:

$$
\tau=\sqrt{\frac{\omega_{\mathrm{D}}}{2 \omega}}, X=\frac{\varepsilon_{0} \mathrm{k}^{2}}{\rho \sqrt{2 v \omega^{3}}}, \quad Y=\frac{\varepsilon_{0} \mathrm{k}}{4 v \rho \omega}, \quad \varepsilon_{0}=\frac{\mathrm{d} \sigma}{\mathrm{d}(\ln \Gamma)}
$$

are adimensional quantities and:

$$
f=\frac{\sqrt{(\sigma / \rho) k^{3}+g k}}{2 \pi}
$$


the dispersion law, $\sigma$ surface tension, $\rho$ water density, $g$ acceleration of gravity, $\mathrm{k}$ wave number, $v$ kinematics viscosity; the constant characteristic parameters of the film are: elasticity modulus $\varepsilon_{0}$, surface concentration $\Gamma$, and characteristic frequency $\omega_{\mathrm{D}}$, which, for soluble films, depends upon the diffusional relaxation, and for insoluble films, depends upon structural relaxation between intermolecular forces. In (1) a plus sign refers to soluble films, while a minus sign indicates insoluble films.

Spectral measurements carried out both in tanks and in many oceanic sites on slicked waters clearly show this damping effect. The ratios between spectra measured in pure water and in water covered by film have a maximum in the 2-10 Hz range (Cini et al. 1983). From observed ratios and theory it is possible to deduce rheological parameters, such as the relaxation characteristic frequency and the visco-elastic modulus, as well as the film concentration or fragmentation (Fiscella et al. 1995).

Soluble (adsorption) films have been thoroughly investigated (Lucassen-Reynders and Lucassen, 1969). Typical values of the diffusional characteristic frequency $\omega_{\mathrm{D}}$ observed in saturated conditions are in the order of 10-2 rad/s, or smaller (Loglio et al. 1986). Hence, in good approximation, soluble films are characterized by setting $\omega_{\mathrm{D}}=0$. With this condition one can verify that in soluble films the Marangoni waves are too highly attenuated to be of practical interest. The study of insoluble (spreading) films on sea surface (Lucassen 1982, Cini et al. 1983) have indicated the possibility of obtaining qualitative data on polluting films by analysing the short gravity portion of the wave spectrum of a breezy sea.

\subsection{Experimental evidences}

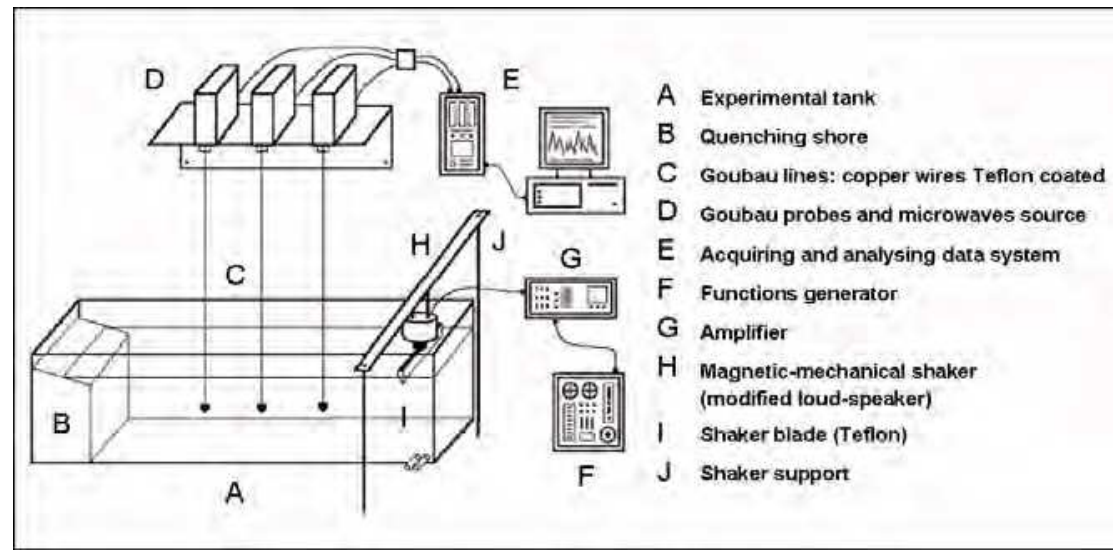

Fig. 1. Experimental setup for wave damping measurements

By means of a microwave probe (Fiscella et al. 1982), short gravity and capillary wave domain of the sea spectra have been investigated in a variety of field situations. Viscoelastic characteristics of insoluble films prepared in laboratory from pure surfactants (e.g. palmitic acid methyl ester, hexadecyl trimethyl ammonium bromide) have been then studied by tests including spectral measurements performed in a wind tunnel, and attenuation measurements of several monochromatic mechanically generated waves in the maximum damping ratio range (Fiscella et al. 1985b). Comparisons between the observed data and 
theory have produced relaxation characteristic frequencies $\omega_{\mathrm{D}}$ in the range 7.5 to $11 \mathrm{rad} / \mathrm{s}$, and elasticity modulus $\varepsilon_{0}$ in the range $5.0 \cdot 10^{-3}$ to $2.210^{-2} \mathrm{~N} / \mathrm{m}$. Such values produce a damping ratio for the Marangoni mode revealing that the insoluble films sustain both wave modes.

The results of measurements obtained in laboratory using oleyl alcohol as surfactant are presented below; the surfactant organic compound, in fact, have been already used in past experiments as a good representative of hydrophobic surface substances (Trivero et al. 2001).

Oleyl alcohol was used as surfactant substance to study damping effect by meanS of a laboratory tempered glass tank (dim. $298 \times 27.3 \times 29 \mathrm{~cm} ; 235$ litres volume) and an interferometric microwave wave gauge which measures wave heights on an absolute, selfcalibrating scale with high accuracy; this apparatus has been already used in sea surface measurements (Fiscella et al. 1982). The basic element of this probe is a Teflon coated wire. The lower end of this wire is held vertically straight and dipped in water, while the other end is fed by a microwave source. The microwave energy travels downwards, confined to a close proximity of the coated wire (Goubau line). The contact with the water acts as a short circuit, giving origin to a reflected wave. In condition of good matching of the microwave system the field in the transmission line has a standing wave pattern, which is uniquely determined by the location of the water contact with the coated wire.

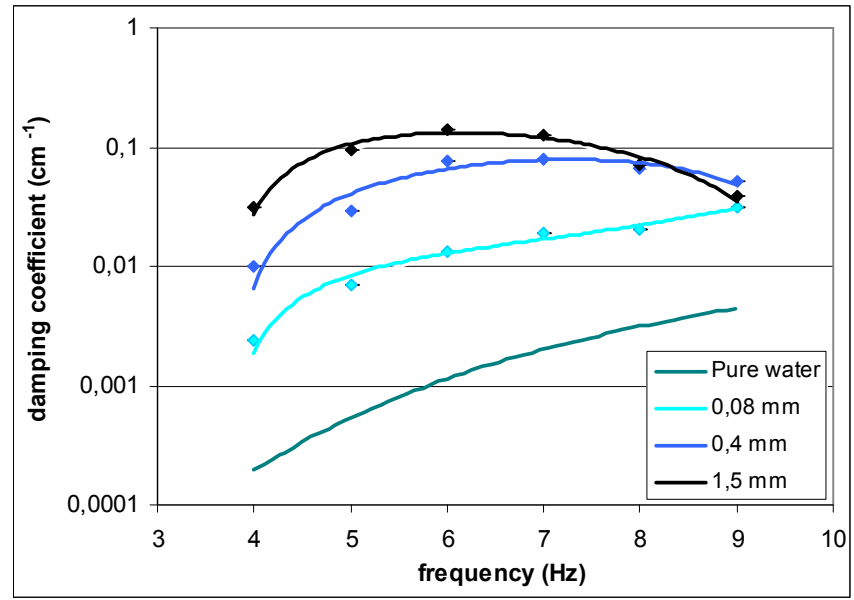

Fig. 2. Damping coefficient vs. frequency for different film thickness

Power spectra are obtained by data segmentation, Hanning windowing, FFT operation and subsequent power spectra meaning. In a Goubau line with a copper wire radius of $0.6 \mathrm{~mm}$ and coating thickness of $0.3 \mathrm{~mm}$, the radius of the area in which $50 \%$ of the propagated power is concentrated is: $\rho_{\mathrm{o}}=2.4 \mathrm{~mm}$. This area includes the meniscus (for clean water) and implies a Voltage Standing Wave Ratio $\geq 2$. In this case the liquid wavelength $4 \rho_{o}$, i.e., 26 $\mathrm{Hz}$, may be considered the upper frequency limit of the probe. The measurement of $\mathrm{z}$ can thus be accomplished with accuracy of the order of few micrometers. In laboratory and clean water conditions the time series of the sea water elevation are affected by instrumental errors of few micrometers and frequency spectra can be obtained without distortion up to 20 
Hz. The results obtained are in accord to theory of rheology and confirm even in laboratory the damping wave effect showed by surfactant substances at sea surface.

The experimental apparatus, shown in figure 1, consists of a three Goubau line coated wire system. The wires are positioned along wave direction at proper distance in order to measure spatial damping of the waves mechanically generated. The same apparatus can be used at the sea to obtain information about directional wave spectra.

Damping measurements versus frequency were performed adding a known oleyl alcohol quantity in order to obtain a fixed growing film thickness. Figure 2 shows the damping coefficients for pure water and different film thicknesses.

\section{SAR observation of marine surface}

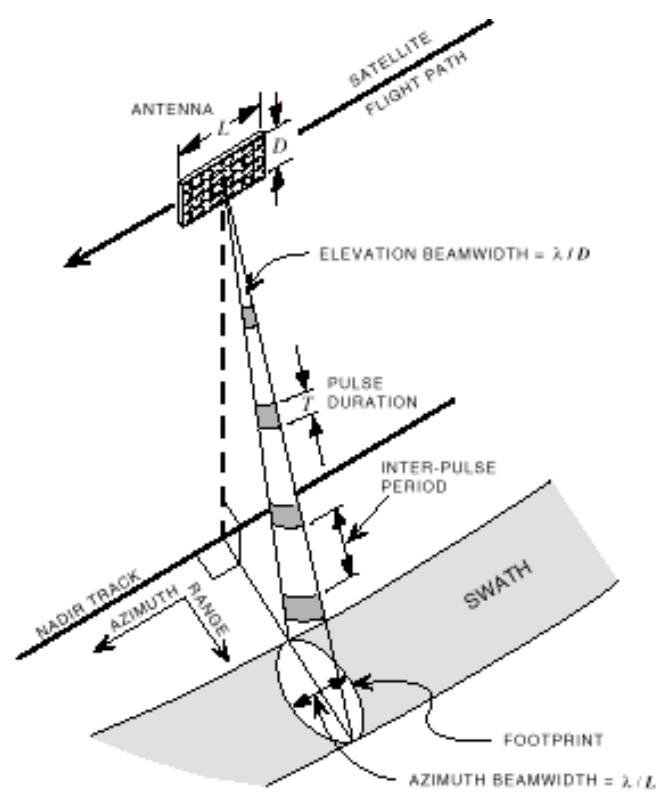

Fig. 3. SAR acquisition geometry

The SAR is basically a conventional radar instrument, carried by a mobile system such as aircraft or satellite. The main principle of SAR is the antenna synthesis: when moving, the target is observed from different angles and the backscattered signals are put together. Observation is lateral rather than perpendicular to the earth's surface (figure 3).

The electromagnetic waves, used by SAR, are in the microwave region. Wavelengths are in the range from 0.1 to $100 \mathrm{~cm}$ and it is divided in different bands with a standard nomenclature. Table 1 summarizes the most utilised frequencies and their characteristics.

The basic mechanism involved is the normalised radar cross-section which, for incidence angles higher than $20^{\circ}$, is proportional to the spectral energy density of the sea waves having wavelength $\Lambda$ that obey the Bragg resonance condition: 


$$
\Lambda=\frac{\lambda}{2 \sin \vartheta}
$$

where $\lambda$ is the radar wavelength and $\theta$ the incidence angle of radar beam; electromagnetic waves, backscattered from every water wave front, sum in phase producing a well detectable echo (figure 4). For low incidence angles the backscatter is due to specular reflection. The sea waves, which are Bragg resonant with microwaves employed by the SAR systems, fall in the short gravity wave region where is found a maximum in the ratio between spectra measured in pure water and in water covered by film.

\begin{tabular}{|c|c|c|}
\hline Band designator & Frequencies $(\mathrm{GHz})$ & Wavelength in Free Space $(\mathrm{cm})$ \\
\hline L band & 1 to 2 & 30.0 to 15.0 \\
\hline S band & 2 to 4 & 15.0 to 7.5 \\
\hline C band & 4 to 8 & 7.5 to 3.8 \\
\hline$X$ band & 8 to 12 & 3.8 to 2.5 \\
\hline Ku band & 12 to 18 & 2.5 to 1.07 \\
\hline K band & 18 to 27 & 1.7 to 1.1 \\
\hline Ka band & 27 to 40 & 1.1 to 0.75 \\
\hline V band & 40 to 75 & 0.75 to 0.40 \\
\hline W band & 75 to 110 & 0.40 to 0.27 \\
\hline
\end{tabular}

Table 1. radar bands

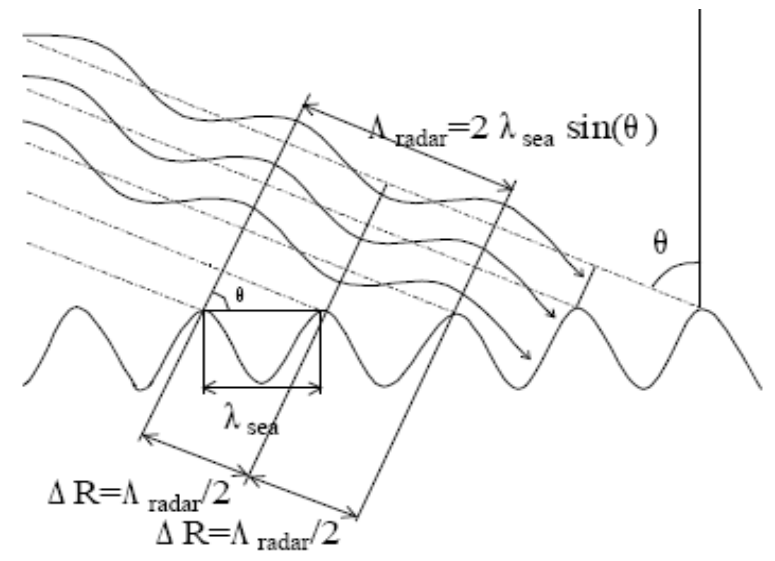

Fig. 4. Bragg condition between water waves and radio waves

Remote sensing radars are usually designed to transmit either vertically polarised or horizontally polarised radiation. Likewise, the radar can receive either vertically or horizontally polarised radiation, or sometimes both. Polarisation planes are designated by the letters $\mathrm{H}$ for Horizontal and $\mathrm{V}$ for Vertical. When the polarisation of received radiation is the same as the transmitted radiation, the image is said to be like-polarised When the polarisation of received radiation is the opposite of the transmitted radiation, the image is said to be cross-polarised.Cross polarisation requires multiple-scattering by the target and therefore results in weaker backscatter than like-polarisation. Cross-polarised signals are 
sometimes too weak to produce a good image, although the use of multiple polarization can help in revealing sea surface characteristics (Brekke and Solberg 2005).

\subsection{Wind vector extraction}

Sea surface roughness is directly related to external forces such as wind and currents; for this reason, data from SAR observation can be used to compute sea surface parameters.

When dealing with surface slick observation, the knowledge of wind vector plays a key role for at least two reasons. First, surface slicks can be detected if wind intensity is within a range of $2 \mathrm{~m} / \mathrm{s}$ and $20 \mathrm{~m} / \mathrm{s}$; a weaker wind cannot produce roughness and therefore the sea area appears as flat whether a slick is present or not. Conversely, a very strong wind can produce roughness even on a slick covered area. Secondly, wind forcing and wind induced currents are directly responsible for slick evolution (drift and weathering); therefore the wind vector is fundamental in estimating the fate of a surface slick.

Wind data are can be get from in-situ measurements (e.g. buoys), meteorological models or satellite - borne scatterometers (with poor spatial resolution). In last years, studies have been carried out in order to find suitable methods to extract wind field from the SAR image itself.

A popular approach is to use a geophysical model function (GMF), e.g. a nonlinear function who describes the NRCS as a function of, wind speed (normalized to $10 \mathrm{~m}$ height), wind direction, incidence angle and azimuth angle with respect to wind direction); radar frequency is also taken into account. Using numerical techniques to invert such a function, wind speed can be obtained from SAR image (assuming to have the wind direction). For satellite - borne SAR operating at C-band and vertical (VV) polarization in transmission and reception, several empirical GMFs have been developed and validated; the most popular are:

- CMOD4 (Stoffolen and Anderson, 1997), utilising ECMWF (the European Center for Medium-Range Weather Forecast) weather model results as calibration data;

- CMOD_IFR2 (Quilfen et al., 1998) developed at Ifremer-France and calibrated against in situ measurements, (buoys data and ECMWF model results);

- $\quad$ CMOD5 (Hersbach, 2003), an upgraded version of CMOD4.

These functions are applied on SAR data from ERS-1, ERS-2 and ENVISAT satellites. Other similar approaches have been defined for L-band data or from C-band horizontal polarization data.

However, to measure wind speeds from SAR images using such kind of methods, it is necessary to have the wind direction. A first approach is to assume a fixed direction for a whole SAR image, for example interpolating the wind direction from scatterometer data or atmospheric models.

In last years, several attempt have been done to extract the wind direction field from the image itself, exploiting linear features aligned with the wind direction are visible.

A popular method is the Fast Fourier Transform (FFT) method (Gerling, 1986): the Fourier spectrum of the SAR image is computed and the main spectral energy is located perpendicular to the orientation of the wind streaks, giving a wind direction with a $180^{\circ}$ directional ambiguity.

A recently developed wind direction estimation method is the local gradient (LG) method, which derives the orientation of the wind streak by evaluating the local gradient on different scales (Horstmann and Koch, 2005; Horstmann et al., 2002; Koch, 2004). Alternative 
approaches such as wavelet analysis (Du et al., 2002; Fichaux and Rachin, 2002) and variance method (Wackerman et al., 2003) have also been applied.

A comprehensive review on wind estimation methods can be found in (Lin et al. 2008).

\subsection{Surface slicks detection}

It is well known that the surfactants are responsible for sea wave damping and reflectivity modulation over a broad range of frequencies from the visible to the microwave regions of the spectrum. Measurements of slick-induced damping of short-gravity ocean waves excited by the wind provide useful data for the investigation and characterization of ocean microlayers on a thermodynamic basis. By means of a theoretical model one can infer the soluble or insoluble nature of the substance forming the film itself, the rheological parameters and the surface film fragmentation.

Among all monitoring ways, multi-frequency radar and SAR are powerful tools for the detection and characterization of substances forming sea surface film.

Wave damping, due to surface slick, modifies the backscattering of electromagnetic waves and hence it is possible to optically detect slicks (Scully-Power 1986) and measure their characteristics by means of radars from platform, airborne and satellite (Fiscella et al. 1985b, Espedal et al. 1996, Trivero et al. 2001). However, dark areas can be also due to atmospheric effects (Alpers, 1995; Melsheimer et al., 1998).
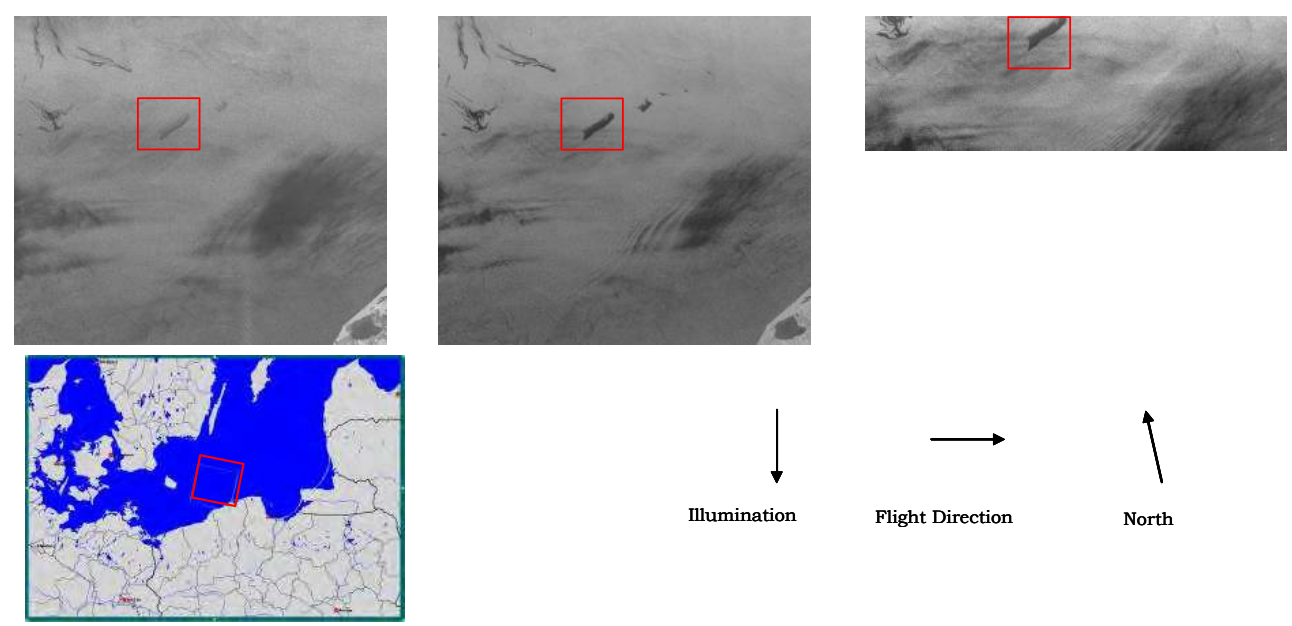

Fig. 5. Oil slick observed by L-band (left), C-band (center), X-band (right) 


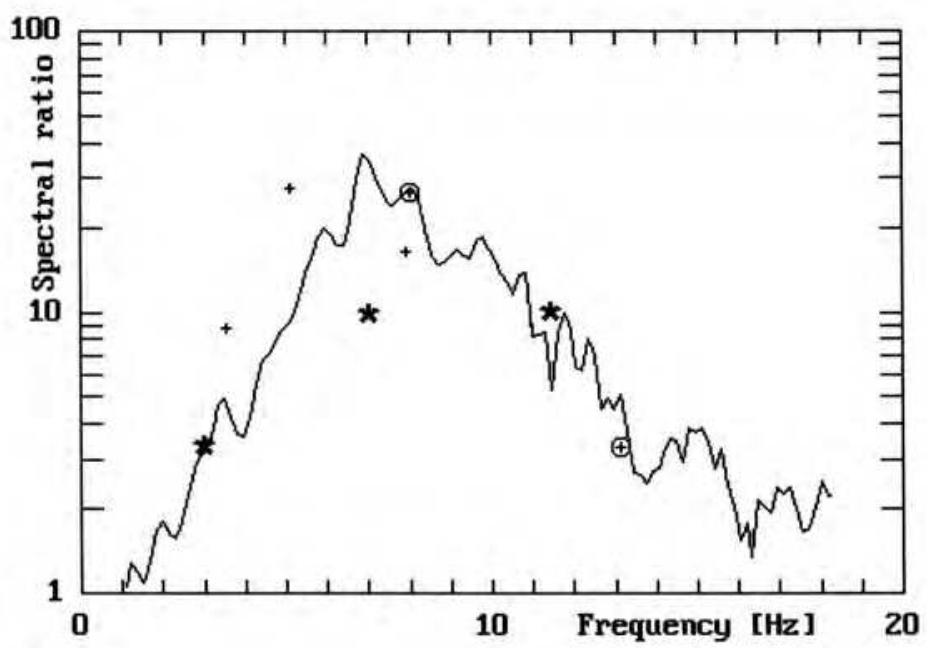

Fig. 6. Comparison among damping ratios obtained by radars and by the wave gauge.

The ability of multi-frequency SAR to characterize surface films was tested with data obtained during an experiment in October 1990 in the northern Adriatic Sea, when an airborne SAR flew over a research platform, on board of which, time series of radar backscatter as well as high frequency wave spectra were measured (Trivero et al. 2001). The obtained results were confirmed by analogous experiment performed in the North Sea during the first SIR-C/X-SAR mission in 1994 (Gade et al. 1998); in that mission, the NASA's space shuttle carried SAR instruments at three different bands simultaneously looking at the same areas. Figure 5 shows how the same surface slick is seen in a different way by three different frequencies;

In June 1991 in the Gulf of Genoa (Italy) another similar experiment was performed observing slicked area after oil-tanker accident (Trivero et al. 1998).

In figure 6, the full line is the display of the ratio of the power spectral components from gauge data between pure and slick-covered water; the three $(+)$ and the two $(\oplus)$ points are the plots of $\sigma d \sigma_{s}$ from multi-frequency scatterometer data and from SAR-580 images, respectively. The three $\left(^{*}\right)$ points are the plots of $\sigma_{d} / \sigma_{s}$ from SIR-C/X-SAR images.

The experimental results showed that multi-frequency SAR is an ideal instrument to monitor sea surface substances, since SAR data contain information about the spectral components affected by damping.

\section{Available SAR data}

The use of satellite - borne SARs for earth observation is a well tested and established technique. The history begun on the $28^{\text {th }}$ June of 1978 when Seasat, the first Earth-orbiting satellite designed for remote sensing, was launched.

Seasat, managed by NASA's Jet Propulsion Laboratory (JPL), operated for 105 days until October 10, 1978, when a short circuit occurred in the satellite electrical system; during the mission, the onboard L-band SAR acquired approximately 42 hours of data. Despite this 
unhappy ending, Seasat played a key role for earth observation by demonstrating the feasibility of global satellite monitoring of sea surface and by helping scientists in defining technical requirements (Evans et al. 2005).

In the following years a number of satellites were launched, carrying SAR instruments with very different characteristics. Here, we want to review the currently operating missions, with data easily available for scientific and/or commercial use; for these reasons, only currently civil operational missions are described, while military only missions have been omitted as well as sensors which have reached the end of their operational life.

For every sensor an overview is given about frequency, resolutions, revisitation frequency and data distribution policies; for detailed information, the satellite owner and contact details are reported. All the information is correct at the publishing date.

\subsection{European Remote Sensing (ERS) satellites}

Managed by European Space Agency (ESA), ERS-1 satellite was launched in 1991 and completed its operation in 2000, overlapping with the new ERS-2 launched in 1995 and still operating.

ERS-2 SAR works on C band at fixed VV polarisation. Its best spatial resolution is $12.5 \mathrm{~m}$, but limited to $5 \mathrm{~km} \times 5 \mathrm{~km}$ imagettes in "wave mode" acquisition. It can also operate in wave mode at $30 \mathrm{~m}$ spatial resolution with a $100 \mathrm{~km}$ swath.

Full documentation is available on ESA earth observation website http://earth.esa.int/ers/ while data availability can be checked online via the EOLI catalogue (http://earth.esa.int/EOLi/EOLi.html), also allowing online ordering for ftp delivery. Different prices and data policies apply for scientific/non-commercial use rather than commercial exploitation.

\subsection{Envisat satellite}

Designed and built by ESA, launched in 2002 with the aim to be the ERS follower, Envisat carries an improved C-band SAR sensor as well as a number of other active and passive instruments.

Envisat SAR best spatial resolution is $\sim 30 \mathrm{~m}$ for a $\sim 100 \mathrm{~km}$ swath; multiple polarization modes are available $(\mathrm{VV}, \mathrm{HH}, \mathrm{VH}, \mathrm{HV})$. A wide swath mode $(\sim 400 \mathrm{Km})$ with a $150 \mathrm{~m}$ spatial resolution is available.

It has a dedicated section on the ESA website (http://envisat.esa.int/); also Envisat data are available on EOLI catalogue.

\subsection{Radarsat satellites}

Designed and built by the Canadian Space Agency, the Radarsat - 1 satellite was launched in 1995. It operates in C-band with fixed $\mathrm{HH}$ polarization; seven imaging modes are available with different swaths (from 50 to $500 \mathrm{~km}$ ) and different spatial resolutions (from 8 $\mathrm{m}$ to $100 \mathrm{~m}$ )

Radarsat - 2, launched in December 2007, is an enhancement of the previous sensor; all polarization modes are now available and a new "ultra fine" acquisition mode ( $3 \mathrm{~m}$ pixel and $20 \mathrm{~km}$ swath) can be operated. Moreover, Radarsat -2 is able to look on both right and left sides with a switch time of a few minutes, allowing more flexibility on selecting the target zone. 
Radarsat images are distributed by MacDonald, Dettwiler and Associates Ltd. (MDA), a Canada based firm (http://gs.mdacorporation.com/products/sensor/index.asp).

\subsection{Terrasar satellite}

The TerraSAR-X Earth observation satellite is a joint venture being carried out under a public-private-partnership between the German Aerospace Center DLR and EADS Astrium GmbH.; TerraSAR-X was launched on June 15th, 2007 and has been in operational service since January 2008 ; it operates on X-band with single, dual and quad polarization. There are three operational imaging modes: SpotLight (1m resolution, $10 \mathrm{~km}$ swath); StripMap ( $3 \mathrm{~m}$ resolution, $30 \mathrm{~km}$ swath) ; ScanSAR (18 m resolution, $100 \mathrm{~km}$ swath).

The exclusive commercial exploitation rights are held by the geo-information service provider Infoterra GmbH (http://www.infoterra.de/), while data access for scientific (non commercial) use is directly managed by DLR.

\subsection{Advanced Land Observing Satellite (ALOS)}

Designed and managed by the Japanese space agency JAXA, ALOS was launched in 2006 being operational in October. It carries, together with other instruments, an L-band SAR (named PALSAR) able to acquire in single polarisation (HH or $\mathrm{VV}$ ) or dual polarisation $(\mathrm{HH} / \mathrm{HV}$ or $\mathrm{VV} / \mathrm{VH})$ modes. The best available resolution is $10 \mathrm{~m}$ with $70 \mathrm{~km}$ swath; the widest swath is over $250 \mathrm{~km}$ at $100 \mathrm{~m}$ resolution.

More information can be found at JAXA (http://www.eorc.jaxa.jp/ALOS/en/index.htm) as well as ESA (http://earth.esa.int/ALOS/) websites; ESA is also responsible for ALOS data distribution in Europe, Africa and Middle East; ALOS images are available on the above mentioned EOLI catalogue.

\subsection{Cosmo - SkyMed constallation}

Since late 90s the Italian Space Agency ASI started to design a multi - purpose Earth Observation System devoted to providing products and services for military and civil use through an integrated approach (Dual Use System). The decision to build a constellation was driven by the need for the shortest revisit time with the aim to exploit data in critical applications such as risk management and environmental monitoring (Rum 2000).

The first three satellites of the COSMO-SkyMed constellation are already in orbit and operational; the launch of the fourth satellite is planned for 2010. The carried sensor is an Xband right and left looking SAR with a maximum spatial resolution of $1 \mathrm{~m}$ (on a $10 \mathrm{~km}$ swath); the "huge" acquisition mode offers a $100 \mathrm{~m}$ resolution with a $200 \mathrm{~km}$ swath; all polarization modes are available.

Operational mode can be set up in three ways (routine, crisis and very urgent) allowing the system to respond to different needs in terms of required programming latency. A User Request (in the case of the first level of SAR standard products) can be satisfied in 72 hours for the system working in routine mode, 36 hours for the crisis mode and 18 hours for the very urgent mode. The management of a constellation rather than a single satellite, as well as the high number of degrees of freedom in acquisition management, pose new issues in operational management (Bianchessi and Righini, 2008).

The commercial distribution rights for Cosmo - SkyMed images have been recently granted to e-GEOS (http://www.e-geos.it/), a new entity owned $80 \%$ by the private firm Telespazio 
and $20 \%$ by ASI. Technical documentation about Cosmo - SkyMed satellites and products can be found on e-GEOS website.

\section{Pollution detection algorithms}

Damped areas appear as dark spots on SAR images; however, different features are clearly identifiable because of their own geometric characteristics. For example, oil slicks usually have a linear shape with well defined contours, whilst natural surfactant appears in a different way (figure 7). An expert photo interpreter is able to distinguish between categories.
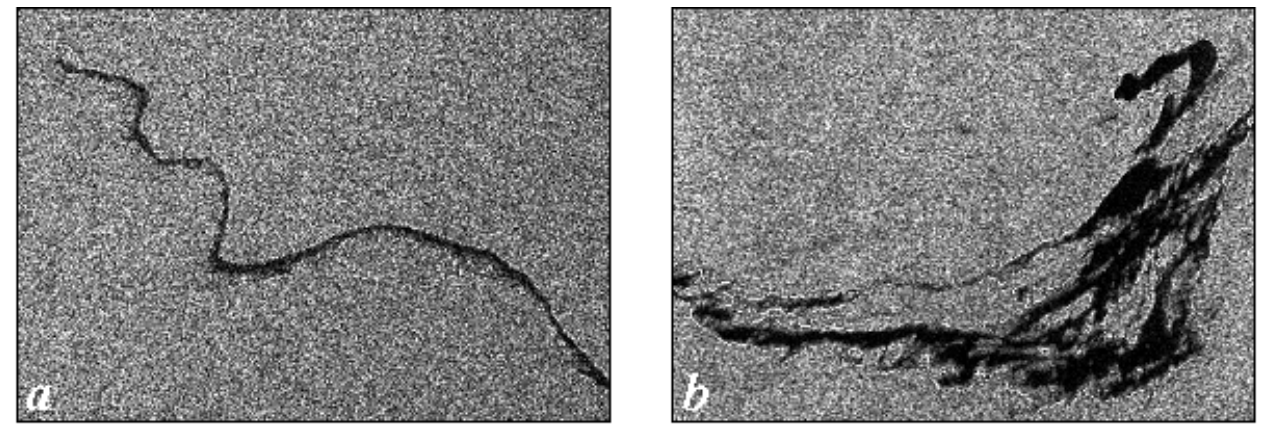

Fig. 7. Example of oil spill (a) and look-alike feature (b) in SAR images

Since SAR images were available, a number of attempts have been done in order to develop and test automatic procedures for oil spill detection, with the aim OF definING A new instrument for real time analysis of satellite images in order to prevent pollution. Here we want to present some exempla of different approaches based on various mathematical techniques.

\subsection{Statistical techniques}

Here we describe a procedure, named "Oil Spill Automatic Detector" (OSAD), able to distinguish oil spills from other similar sea surface features (look-alike) in SAR images using a statistical approach; during last years, the procedure has been updated (Fiscella et al. 2000, Nirchio et al. 2002, Nirchio et. al 2005a, Nirchio et al. 2005b). It considers both the radiometric and the geometric characteristics of the areas being tested. In order to minimize the operator intervention, it adopts automatic selection criteria to extract the potentially polluted areas from the images.

The related operational activities are carried out at the Matera Geodesy Space Centre, where the Italian Space Agency Processing and Archiving Facility (PAF) for the European Remote Sensing (ERS) satellite sensor data and the 'Telespazio' acquisition facility are located. A satellite ground station has been operative in Matera (Italy) since November 1999. It acquires data trasmitted down by the European satellites ERS 2 and Envisat. The facility is composed of an $8 \mathrm{~m}$ main dish, a down converter chain and a direct ingestion sub system. The acquisition area spans from the North Sea to the Red Sea including the entire Mediterranean basin. 
The acquired data are first recorded and screened for evaluating the quality parameters, and then a browse image is generated. At this point data are available for processing and distribution to end-users. An operator inspects the browse image, covering an area about $4000 \mathrm{~km}$ long and $100 \mathrm{~km}$ wide, and selects those frames $100 \mathrm{~km} \times 100 \mathrm{~km}$ which appear affected by oil spill. The next step foresees the production of the full resolution image. This can be analysed by OSAD that provides the probability that the suspected area is affected by an oil spill. The land, eventually present in the image, is masked to allow the identification of dark areas potentially interested by oil spills. A threshold is computed, its value depends on the average image intensity from which the image standard deviation has been subtracted. Those areas whose average backscattering is lower than the threshold are further screened for retaining those whose dimensions are larger than $0,3 \mathrm{~km}^{2}$ and smaller than 10 $\mathrm{km}^{2}$. The small regions are rejected because these eventual slicks are not significant; usually they disappear from images in a short time. The large areas are also rejected because they are probably due to lack of wind. At the end of the process, several analysis are performed on the remaining slicks candidates, the probability the area under test is affected by a spill is computed and a detection report is generated and sent to the responsible authority.

Before operational use, the system must be tuned; this is done by means of a training dataset, composed by images that have been classified by an expert photointerpreter as "oil spill" or "look-alike"; uncertain images are discarded. For every image family, geometric and radiometric characteristics are computed; for every characteristic, the data distribution is evaluated in order to find significant parameters for both oil spills and look-alikes.

In the operational use, every acquired image is first calibrated and the land is masked. On sea areas, the significant values are evaluated and then compared with the previously described statistical distributions, in order to define the probability to be an oil spill. This probability is given as a percentage ("score") where 0 is the lookalike and $100 \%$ in an oil spill.

The first tuning of OSAD system has been done on a set of SAR images corresponding to 153 cases of oil spill and 237 cases of look-alike detected during 1999 in the Mediterranean Sea using ERS-1/2 SAR Precision Image Product (PRI) which dimensions are $100 \times 100 \mathrm{~km}$. The method has demonstrated an a priori percentage of correct classification higher than $90 \%$, it is easy to apply and able to determine the identification probability in an automated way (Nirchio et al. 2005b).

Another statistical approach was proposed by Solberg et al. (1999); the procedure consists of first detecting dark spots in the image, then computing a set of features for each dark spot, before the spot is classified as either an oil slick or a "look - alike". The classification rule is constructed by combining statistical modelling with a rule-based approach. Prior knowledge about the higher probability for the presence of oil slicks around ships and oil platforms is incorporated into the model. In addition, knowledge about the external conditions like wind level and slick surroundings are taken into account. The algorithm accuracy is $94 \%$ for the oil slicks and $99 \%$ for the look-alikes.

\subsection{Neural network approach}

An artificial neural network, usually called "neural network", is a mathematical model or computational model that tries to simulate the structure and/or functional aspects of biological neural networks. It consists of an interconnected group of artificial neurons and processes information using a connectionist approach to computation. 
In more practical terms neural networks are non-linear statistical data modeling tools. They can be used to model complex relationships between inputs and outputs or to find patterns in data. It can be thought as an adaptive system that changes its structure based on external or internal information that flows through the network during the learning phase.

Using an approach similar to that described on previous paragraph, Calabresi et al. (1999) used neural networks in order to find specific values identifying oil slicks, chosen from a given set of parameters. Here the network input was a vector containing the values of a set of features previously calculated.

Usually the oil spill candidates (that is the dark areas on SAR image) are identified with their geometric and radiometric parameters, then a classification algorithm is applied. In Topouzelis et al. (2007) two different neural networks are used: one to detect dark spots on sea surface and another to classify the previously found areas as oil spills or look-alikes. The proposed method shows good results in detecting dark formations and discriminating oil spills from look-alikes as it detects with an overall accuracy of $94 \%$ the dark formations and discriminate correctly $89 \%$ of examined cases. For dark area detection the network unit is the pixel, while for classification is a vector made of ten parameters.

It is worth to note how a neural network approach has been used to classify samples of unknown crude oils and distilled fuels on the basis of the results from standard chemical analysis (Fonseca et al. 2006, Fernandez - Varela et al. 2008).

\subsection{Other techniques}

A number of different mathematic techniques can be found in literature for sea surface detection and characterisation of surface slicks.

As previously said, the first step is the determination of dark areas on SAR image, due to low backscattering levels. A first approach is described by Skøelv and Wahl (1993) for ERS-1 SAR images). A similar approach is described in Vachon et al. (1998) and Manore et al. (1998). Solberg et al. (1999, 2003) apply an adaptive algorithm where the threshold is dynamically set at $\mathrm{k} \mathrm{dB}$ below the mean value estimated in a moving window.

Canny (1986) started the use of hysteresis thresholding, later applied by Kanaa et al. (2003)

An approach based on the Laplace of Gaussian (LoG) and Difference of Gaussian (DoG) operators is described in Change et al. (1996) and Chen et al. (1997).

Liu et al. (1997) and $\mathrm{Wu}$ and Liu (2003) proposed the use of wavelet analysis in ocean feature detection, including oil spills. Mercier et al. (2003) suggest a segmentation method based on detecting local variations of the wave spectra. Fuzzy logic was investigated as a since mid 90s (Barni et al. 1995)

Fractal mathematics is also used for classification purposes (Keller et al., 1989; Benelli and Garzelli 1999; Gade and Redondo 1999). The topic is still studied and new results presented (Marghany et al . 2009).

Even though we here focus on single frequency and single polarization SAR images, it is worth mentioning the possibility of a discrimination algorithm based on differences in multi-frequency and multi-polarization signatures. Gade et al. (1996) did some experiments to investigate whether spaceborne L-, C- and X-band multipolarization SARs are capable of discriminating between films of different chemical properties, and found that discrimination is only possible at low to moderate wind. Maio et al. (2001) propose such an algorithm for discrimination between oil spills and lookalikes. 


\subsection{SAR limitations}

It must be observed that not always SAR is able to reveal oil spills; even when detection is made only the thicker part, typically covering only $10 \%$ of the whole oil spills area, is imaged (Sabins 1997).

The detection of oil slicks/spills in SAR images strongly depends on the wind speed at the sea surface. Under low wind speed, typically between 0 and 2-3 $\mathrm{ms}^{-1}$, the sea surface looks dark on SAR images. In this case the wind-generated waves are not already developed and oil films look dark on a dark background: detection in this case is impossible. Wind speed between 3 and $6 \mathrm{~ms}^{-1}$ is ideal for oil slick detection, the sea surface roughness is developed and oil slicks appear as dark patches on a bright background. However, when wind speed reaches 10-12 $\mathrm{ms}^{-1}$, detection is impossible again or obstructed due to the redistribution of oil spills/slicks by the surface waves and wind-induced mixing in the upper ocean layer (Scott 1986); in this case becomes determinant the compactness of film. As the result slick disappears from the sea surface and SAR imagery. The upper wind speed threshold for spill detection with SAR is suggested to be between 10 and $14 \mathrm{~ms}^{-1}$ (Gade and Ufermann 1998, Ivanov 2000). In the Mediterranean Sea it was demonstrated that oil spills can be detected from SAR images if the wind speed results between $2 \mathrm{~ms}^{-1}$ to $10 \mathrm{~ms}^{-1}$; the SAR capability in detecting oil spills has given good results at open sea, while in the near-shore region the detection percentage drops quickly, because in these cases the effect of wind sheltering becomes determinant, that is, the wind screening effect caused by the local topography on the areas near-shore (Nirchio et al. 2005b).

When a slick is detected by SAR, it is not easy to know its evolution state and as a consequence its age. The behaviour of oil spill on the sea surface significantly depends on its important physical-chemical properties, such as viscosity, density, surface tension and elasticity. Moreover, crude oil is a complex mixture of different chemical components including heavy and light fractions. Typically, crude oil can be detected during its evolution in the sea in different phases of age: oil spill, oil film, emulsion (for the first time oil-water emulsion and then water-oil emulsion), blue shine and aggregates. During the lifetime of oil spill in the sea it will be exposed to a number of weathering processes, which dramatically influence physical-chemical properties: spreading, drift, evaporation, dispersion, emulsification, bacterial degradation and photo oxidation (Kotova et al. 1996). With time the physical-chemical properties of oil spills are changed due to effect of these processes. These processes play important role in oil spill detection using SAR sensors. But relative importance of each process is not still well understood. Direct observation seems to show that big slicks lifetime is greater than small ones; for example in the Prestige (Spain 2002) and Haven (Italy 1991) disasters, the great quantities of oil released into the sea stayed on for a long time, although their SAR detection was not been always possible. An estimate of the quantity of oil observed at sea is also crucial because oil thickness is difficult to measure especially the sea is rough. Moreover, water-in-oil emulsions and viscous oils like heavy crude and fuel oil can vary in thickness from millimetres to several centimetres.

\section{Future advances}

The State-Of-The-Art of sea surface SAR monitoring, as described by this paper, shows good results as well as the possibility of being applied for operational issues. However, some issues have yet to be resolved. 
Revisit time is not yet optimal for real time applications; the preferred way to solve this issue is to combine observation with different satellites, by building constellations or by signing agreements between operators in order to exchange data.

Satellite availability is becoming wider with the launch, scheduled in 2010, of the fourth Cosmo-SkyMed satellite and the two SAOCOM (L-band SAR, managed by the Argentinean space agency CONAE).

While automatic oil spill detection shows good results, characterizing other pollutants is less straightforward; moreover, slick characterization (e.g. to define the chemical composition or slick thickness) is still an open issue. It is possible that the use of multi frequency and multi polarization data will lead to valuable results.

\section{References}

Alpers, W. (1995), Measurement of mesoscale oceanic and atmospheric phenomena by ERS1 SAR. URSI Radio Sci. Bull. 275:14-22.

Alpers, W. \& Hühnerfuss, H. (1988), Radar signatures of oil films floating on the sea and the Marangoni effect. J. Geophys. Res. 93:3642-3648.

Alpers, W. \& Hühnerfuss, H. (1989), The damping of ocean waves by surface films: a new look at an old problem. J. Geophys. Res. 94:6251-6265.

Barni, M.; Betti, M. \& Mecocci, A. (1995). A fuzzy approach to oil spill detection on SAR images. Proc. IGARSS '95, vol. 1 (pp. 157-159).

Benelli, G. \& Garzelli, A. (1999). Oil-spills detection in SAR images by fractal dimension estimation. Proc. IGARSS'99, vol. 1 (pp. 218- 220).

Bianchessi N. \& Righini G. Planning and scheduling algorithms for the COSMO-SkyMed constellation. Aerospace Science and Technology 12 (2008) 535-544

Bock, E. J.; Hara, T.; Frew, N. M. \& McGillis, W. R. (1999) Relationship between air-sea gas transfer and short wind waves, J. Geophys. Res. 104(C11), 25,821-25,831.

Brekke, C. \& Solberg, A. H. S. (2005) Oil spill detection by satellite remote sensing, Remote Sensing of Environment $951-13$

Calabresi, G.; Del Frate, F.; Lichtenegger, I.; Petrocchi, A. \& Trivero P. (1999), Neural Networks for the oil spill detection using ERS-SAR data. IGARSS '99 Workshop, 28 June 1999 (Hamburg, Tammy Stein), 1, pp. 215-217, 1999.

Canny, J. (1986). A computational approach to edge detection. IEEE Transactions on Pattern Analysis and Machine Intelligence, PAMI, 8(6), 679- 698.

Change, L. Y.; Chen, K.; Chen, C.; \& Chen, A. (1996). A multiplayer - multiresolution approach to detection of oil slicks using ERS - SAR image. Proc. ACRS 1996-17th Asian Conference of Remote Sensing, Sri Lanka.

Chen, C. F.; Chen, K. S.; Chang, L. Y.; \& Chen, A. J. (1997). The use of satellite imagery for monitoring coastal environment in Taiwan. Proc. IGARSS'97, vol. 3. (pp. 14241426).

Cini, R. \& Lombardini, P.P. (1978) Damping effect of monolayers on surface wave Motion in a liquid. J. Colloid Interface Sci., 65, pp. 387-389.

Cini, R.; Lombardini, P.P. \& Hünerfuss, H. (1983) Remote sensing of marine slicks utilizing their influence on wave spectra. International Journal of Remote Sensing, 4, 101-110.

Du, Y.; Vachon, P. W. \& Wolf, J. (2002) Wind direction estimation from SAR images of the ocean using wavelet analysis. Can J Remote Sens. 28:498-509. 
Ermakov, S. A.; Zujkova, E. M.; Panchenko, A. R.; Salashin, S. G.; Talipova, T. G. \& Titov, V. I. (1986), Surface film effect on short wind waves. Dyn. Atmos. Oceans 10:31-50.

Espedal, H.; Johannessen, O. \& Knulst, J (1996) Satellite detection of natural film on the ocean surface Geophysical Research Letters, 23, pp. 3151-3154.

Evans, D. L.; Alpers, W.; Cazenave, A.; Elachi, C.; Farr, T.; Glackin, D.; Holt, B.; Jones, L.; Liu, W. T.; McCandless, W.; Menard, Y.; Moore, R. \& Njoku, E. (2005) Seasat-A 25year legacy of success. Remote Sensing of Environment 94 384-404

Fernández-Varela, R.; Andrade, J.M.; Muniategui, S.; Prada, D. \& Ramírez-Villalobos, F. (2008) Identification of fuel samples from the Prestige wreckage by pattern recognition methods. Marine Pollution Bulletin 56 335-347

Fichaux, N. \& Rachin, T. (2002) Combined extraction of high spatial resolution wind speed and direction from SAR images: a new approach using wavelet transform. Can J Remote Sens.; 28:510-6.

Fiscella, B.; Giancaspro, A.; Nirchio, F.; Pavese, P. \& Trivero, P. (2000) Oil spill detection using marine SAR images. International Journal of Remote Sensing, 21, 3561-3566.

Fiscella, B.; Gomez, F.; Pavese, P. \& Trivero, P. (1995) Ocean surface films measured by interferential microwave probe Nuovo Cimento C, 18, 375-383.

Fiscella, B.; Lombardini, P.P. \& Pavese P. (1982) Interferential microwave probe for measuring sea ripples. Nuovo Cimento C, 5, 247-255.

Fiscella, B.; Lombardini, P.P. \& Trivero P. (1985a) Ripple Damping on Water Surface Covered by a Spreading Film: Theory and Experiment. Il Nuovo Cimento, vol.8C, no.5, pp. 491-500, 1985a.

Fiscella, B.; Lombardini, P.P.; Trivero, P.; Pavese, P. \& Cini R. (1985b) Measurements of the Damping Effect of a Spreading on Wind-Excited Sea Ripples Using a Two Frequency Radar. Nuovo Cimento, C8, pp. 175-183,.

Fonseca, A. M.; Biscaya, J. L.; Aires-de-Sousa, J. \& Loboa A. M. (2006) Geographical classification of crude oils by Kohonen self-organizing maps. Analytica Chimica Acta $556374-382$

Frew, N. M.; Goldman, J. C; Dennett, M. R. \& Johnson A. S. (1990), Impact of phytoplanktongenerated surfactants on air-sea gas exchange, J. Geophys. Res., 95(C3), 3337-3352.

Frysinger, G. S.; Asher, W. E.; Korenowski, G. M.; Barger, W. R.; Klusty, M. A.; Frew, N. M. \& Nelson R. K. (1992), Study of Ocean Slicks by Nonlinear Laser Processes 1. Second-Harmonic Generation, J. Geophys. Res., 97(C4), 5253-5269.

Gade, M.; Alpers, W.; \& Bao, M. (1996). Measurements of the radar backscattering over different oceanic surface films during the SIR-C/XSAR campaigns. Proc. IGARSS'96 (pp. 860-862).

Gade, M.; Alpers, W.; Hühnerfuss, H.; Wismann, V. R. \& Lange, P. A. (1998) On the Reduction of the Radar Backscatter by Oceanic Surface Films: Scatterometer Measurements and Their Theoretical Interpretation, Remote Sens. Environ. 66:52-70

Gade, M. \& Redondo, J. (1999). Marine pollution in European coastal waters monitored by the ERS-2 SAR: a comprehensive statistical analysis. OCEANS '99 MTS/IEEE Riding the Crest into the 21st century, vol. 3 (pp. 1239-1243).

Gade, M., \& Ufermann, S. (1998) Using ERS-2 SAR images for routine observation of marine pollution in European coastal waters. Proc. of IGARSS'98, Seattle, USA, July 6-10,.

Gerling, T. W. (1986) Structure of the surface wind field from the Seasat SAR. J Geophys Res. 91:2308-20. 
Goldman, J.C. \& Dennet, M. R. (1983) Carbon dioxide exchange between air and sea water: no evidence for rate catalysis. Science, 220, 199-201.

Hersbach, H. (2003) CMOD5: an improved geophysical model function for ERS C-band scatterometry. European Centre for Medium Range Weather Forecasting (ECMWF) Technical Memorandum. 395:1-50.

Horstmann, J \& Koch, W. (2005) Measurement of sea surface winds using synthetic aperture radars. IEEE Trans Geosci Remote Sens;30:508-15.

Horstmann, J; Koch, W; Lehner, S \& Tonboe, R. (2002) Ocean winds from RADARSAT-1 ScanSAR. Can J Remote Sens. 28:524-33.

Hühnerfuss, H. (1986), The molecular structure of the system water/monomolecular surface film and its influence on water wave damping, Habilitationsschrift, University of Hamburg, Department of Chemistry, Hamburg, Germany, 245 pp.

Hühnerfuss, H.; Alpers, W.; Dannhauer, H.; Gade, M.; Lange, P. A.; Neumann, V. \& Wismann, V. (1996), Natural and man-made sea slicks in the North Sea investigated by a helicopter-borne 5-frequency radar scatterometer. Int. J. Remote Sens. 17:15671582.

Hühnerfuss, H. and Garrett, W. D. (1981), Experimental seaslicks: their practical applications and utilization for basic studies of air-sea interactions. J. Geophys. Res. 86:439-447.

Hühnerfuss, H.; Gericke, A.; Alpers, W.; Theis, R.; Wismann, V. \& Lange, P. A. (1994), Classification of sea slicks by multi- frequency radar techniques: new chemical insights and their geophysical implications. J. Geophys. Res. 99:9835-9845.

Hühnerfuss, H.; Walter, W.; Lange, P. A. \& Alpers, W. (1987) Attenuation of wind waves by monomolecular sea slicks and the Marangoni effect. J. Geophys. Res., 92 , 3961 - 3963.

Ivanov, A. (2000) Oil pollution of the sea on Kosmos -1870 and Almaz-1 radar imagery, Earth Observation \& Rem. Sensing, 15(6), 949-966, 2000.

Kanaa, T.F.N.; Tonye, E.; Mercier, G.; Onana, V.P.; Ngono, J.M.; Frison, P.L.; Rudant, J.P. \& Garello, R. (2003). Detection of oil slick signatures in SAR images by fusion of hysteresis thresholding responses. Proc. IGARSS'03, vol. 4 (pp. 2750- 2752).

Keller, J. M.; Chen, S. \& Crownover, R. M. (1989). Texture description and segmentation through fractal geometry. Computer Vision, Graphics, and Image Processing, 45, 150166.

Koch, W. (2004) Directional analysis of SAR images aiming at wind direction. IEEE Trans Geosci Remote Sens. 42:702-10.

Kotova, L.; Espedal, H.A. \& Johannessen, O.M. (1998) Oil Spill Detection Using Spaceborne SAR: a Brief Review. Proc. 27th Int. Symposium on Remote Sensing Environmental, 8-12 June 1998, Tromso, Norway, 791-794.

Lin, H.; Xu, Q. \& Zheng, Q. (2008)An overview on SAR measurements of sea surface wind, Progress in Natural Science 18 (2008) 913-919

Liu, A. K.; Peng, C. Y. \& Chang, S. Y. (1997). Wavelet analysis of satellite images for coastal watch. IEEE Journal of Oceanic Engineering, 22(1), 9- 17.

Liss, P. S.; Watson, A. J.; Bock, E. J.; Jaehne, B.; Asher, W. E.; Frew N. M.; Hasse, L.; Korenowski, G. M.; Merlivat, L.; Phillips, L. F.; Schluessel, P. \& Woolf. D. K. (1997) Physical processes in the microlayer and air-sea exchange of trace gases. In: The sea surface and global change, Cambridge University Press, New York, 1-33,. 
Lombardini, P.P.; Fiscella, B.; Trivero, P.; Cappa, C. \& Garrett, W. D. (1989) Modulation of the Spectra of Short Gravity Waves by Sea Surface Film: Slick Detection and Characterization with a Microwave Probe. J. Atmosph. Ocean Techn., 6, pp. 882- 890.

Lombardini, P.P.; Piazzese, F. \& Cini, R. (1982) The Marangoni Wave in Ripples on an AirWater Interface Covered by Spreading Film. Nuovo Cimento, C5, pp. 256-263.

Loglio, G.; Tesei, U. \& Cini, R. (1986) Viscoelastic dilatation processes of fluid/fluid interfaces: time-domain representation. Colloid Polym. Sci., 264, 712.

Lucassen, J. (1982), Effect of surface-active material on the damping of gravity waves: a reappraisal. J. Colloid Interface Sci. 85:52-58.

Lucassen-Reynders, E. H. \& Lucassen, J. (1969) Properties of Capillary Waves. Advan. Colloid interface Sci., 2, pp. 347-395,.

Maio, A. D.; Ricci, G. \& Tesauro, M. (2001). On CFAR detection of oil slicks on the ocean surface by multifrequency and/or multipolarization SAR. In Radar conference, 2001. Proceedings of the 2001 IEEE (pp. 351-356).

Manore, M. J; Vachon, P. W.;, Bjerkelund, C.;, Edel, H. R. \& Ramsay, B. (1998). Operational use of RADARSAT SAR in the coastal zone: The Canadian experience. 27th International Symposium on Remote Sensing of the Environment, Tromsø, Norway, June 8-12 (pp. 115-118).

Marghany, M.; Cracknell, A. P. \& Hashim M. (2009) Modification of fractal algorithmfor oil spill detection from RADARSAT-1 SAR data. International Journal of Applied Earth Observation and Geoinformation 11 96-102.

Melsheimer, C.; Alpers, W \&. Gade, M. (1998) Investigation of multifrequency multipolarization radar signatures of rain cells over the ocean using SIR-C/X-SAR data, J. Geophys. Res., 103(C9), 18,867-18,884.

Mercier, G.; Derrode, S.; Pieczynski, W.; Caillec, J. M. L. \& Garello, R. (2003). Multiscale oil slick segmentation with Markov Chain Model. Proc. IGARSS'03, vol. 6 (pp. 35013503).

Nirchio, F.; Sorgente, N.; Giancaspro, A.; Pavese, P.; Ravera, R. \& Trivero, P. (2002) A method to detect oil spill based on SAR images" Proc. OIL SPILL, Rhodes, Sept. 2002.

Nirchio, F.; Sorgente, N.; Giancaspro, A.; Biamino, W.; Parisato, E.; Ravera, R.; Trivero, P. \& Pavese, P. (2005a) Oil spills automatic detection from SAR images. Proc. of the 2004 Envisat \& ERS Symposium, Salzburg, Austria 6-10 September 2004, ESA SP-572.

Nirchio, F.; Sorgente, N.; Giancaspro, A.; Biamino, W.; Parisato, E.; Ravera, R. \& Trivero, P. (2005b) Automatic detection of oil spills from SAR images. International Journal of Remote Sensing, Vol. 26, N. 6, 1157-1174

Onstott, R. \& Rufenach, C. (1992), Shipboard active and passive microwave measurement of ocean surface slicks off the southern California coast. J. Geophys. Res. 97:5315-5323.

Quilfen, Y.; Chapron, B.; Elfouhaily, T.; Katsaros, K.; \& Tournadre, J. (1998), Observation of tropical cyclones by high-resolution scatterometry, J. Geophys. Res., 103(C4), 77677786 .

Rum, G. (2000) The Interest of a Constellation: The COSMO-SkyMed Project. Air E Space Europe, 2 (4), 53-58

Sabins, F .F. (1997) Remote sensing - Principles and Interpretation. W.H. Freeman \& Co, N.Y. Scott, J.C. 1986. Surface films in oceanography. ONRL Workshop Rep. C-11-86. Office of Nav. Res., London, 19-34. 
Scott, J. C. (1986) Surface films in oceanography. ONRL Workshop Rep. C-11-86. Office of Nav. Res., London, 19-34,.

Scully-Power, P. (1986) Navy oceanographer shuttle observations, Mission Report. Naval Underwater Center 2 .2,5.3,

Skøelv, ̊̊. \& Wahl, T. (1993). Oil spill detection using satellite based SAR, Phase 1B competition report. Tech. rep., Norwegian Defence Research Establishment.

Solberg, A. H. S.; Dokken, S. T. \& Solberg, R. (2003). Automatic detection of oil spills in Envisat, Radarsat and ERS SAR images. Proc. IGARSS'03, vol. 4 (pp. 2747-2749).

Solberg, A. H. S.; Storvik, G.; Solberg, R. \& Volden, E. (1999). Automatic detection of oil spills in ERS SAR images. IEEE Transactions on Geoscience and Remote Sensing, 37(4), 1916- 1924.

Stoffelen, A \& Anderson, D. (1997) Scatterometer data interpretation: estimation and validation of the transfer function CMOD4. J Geophys Res 102:5767-80.

Topouzelis, K.; Karathanassi, V.; Pavlakis, P. \& Rokos, D. (2007) Detection and discrimination between oil spills and look-alike phenomena through neural networks. ISPRS Journal of Photogrammetry E Remote Sensing 62, 264-270

Trivero, P.; Fiscella, B.; Gomez, F. \& Pavese, P. (1998) SAR detection and characterization of sea surface slicks. International Journal of Remote Sensing, 19, 543-548,.

Trivero, P.; Fiscella, B. \& Pavese, P. (2001) Sea surface slicks measured by SAR. Il Nuovo Cimento, 24 C, 1, pp. 99-111.

Vachon, P. W.; Thomas, S. J.; Cranton, J. A.; Bjerkelund, C.; Dobson, F. W. \& Olsen, R. B. (1998). Monitoring the coastal zone with the RADARSAT satellite. Oceanology International 98, UK, March 10-13, 10 pages.

Wackerman, C. C.; Horstmann, J. \& Koch, W. (2003) Operational estimation of coastal wind vectors from RADARSAT SAR imagery. In: Geoscience and Remote Sensing Symposium, IGARSS '03. 2:1270-2.

Wei, Y. and Wu, J. (1992), In situ measurements of surface tension, wave damping, and wind properties modified by natural films. J. Geophys. Res. 97:5307-5313.

$\mathrm{Wu}, \mathrm{J}$. (1989), Suppression of oceanic ripples by surfactant - spectral effects deduced from sun-glitter, wave-staff and microwave measurements. J. Phys. Oceanogr. 19:238-245.

Wu, S. Y. \& Liu, A. K. (2003). Towards an automated ocean detection, extraction and classification scheme for SAR International Journal of Remote Sensing, 24(5), 935-951.

Zutic, V. B.; Cosovic, B.; Marcenko, E. \& Bihari, N. (1981) Surfactant production by marine phytoplankton. Mar. Chem., 10: 505-520. 


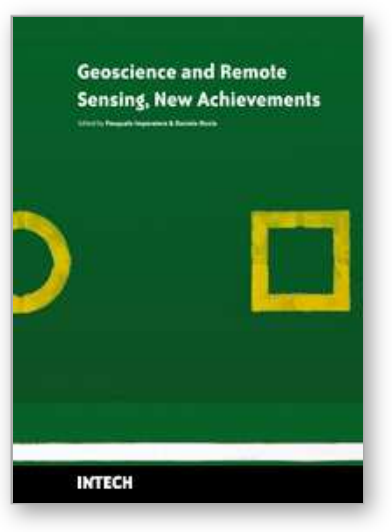

\author{
Geoscience and Remote Sensing New Achievements \\ Edited by Pasquale Imperatore and Daniele Riccio
}

ISBN 978-953-7619-97-8

Hard cover, 508 pages

Publisher InTech

Published online 01, February, 2010

Published in print edition February, 2010

Our planet is nowadays continuously monitored by powerful remote sensors operating in wide portions of the electromagnetic spectrum. Our capability of acquiring detailed information on the environment has been revolutionized by revealing its inner structure, morphology and dynamical changes. The way we now observe and study the evolution of the Earth's status has even radically influenced our perception and conception of the world we live in. The aim of this book is to bring together contributions from experts to present new research results and prospects of the future developments in the area of geosciences and remote sensing; emerging research directions are discussed. The volume consists of twenty-six chapters, encompassing both theoretical aspects and application-oriented studies. An unfolding perspective on various current trends in this extremely rich area is offered. The book chapters can be categorized along different perspectives, among others, use of active or passive sensors, employed technologies and configurations, considered scenario on the Earth, scientific research area involved in the studies.

\title{
How to reference
}

In order to correctly reference this scholarly work, feel free to copy and paste the following:

Paolo Trivero and Walter Biamino (2010). Observing Marine Pollution with Synthetic Aperture Radar, Geoscience and Remote Sensing New Achievements, Pasquale Imperatore and Daniele Riccio (Ed.), ISBN: 978-953-7619-97-8, InTech, Available from: http://www.intechopen.com/books/geoscience-and-remotesensing-new-achievements/observing-marine-pollution-with-synthetic-aperture-radar

\section{INTECH}

open science | open minds

\section{InTech Europe}

University Campus STeP Ri

Slavka Krautzeka 83/A

51000 Rijeka, Croatia

Phone: +385 (51) 770447

Fax: +385 (51) 686166

www.intechopen.com

\section{InTech China}

Unit 405, Office Block, Hotel Equatorial Shanghai

No.65, Yan An Road (West), Shanghai, 200040, China

中国上海市延安西路65号上海国际贵都大饭店办公楼405单元

Phone: +86-21-62489820

Fax: $+86-21-62489821$ 
(C) 2010 The Author(s). Licensee IntechOpen. This chapter is distributed under the terms of the Creative Commons Attribution-NonCommercialShareAlike-3.0 License, which permits use, distribution and reproduction for non-commercial purposes, provided the original is properly cited and derivative works building on this content are distributed under the same license. 